\title{
Attentiveness Toward Oral Care Needs for Preventing Aspiration Pneumonia: A Comparative Study of Indonesian Care Workers in Japan and Indonesia
}

Yuko 0. Hirano ( $\nabla$ hirano@nagasaki-u.ac.jp )

Nagasaki Daigaku https://orcid.org/0000-0002-5430-8962

Susiana Nugraha

Universitas Respati Indonesia

Hiroyasu Shiozu

Chubu Daigaku

Misako Higashijima

Nagasaki Daigaku

Tri Budi W Rahardjo

Universitas Respati Indonesia

\section{Research}

Keywords: older adults, oral care, care skills transfer, Indonesia, Japan, EPA care workers

Posted Date: July 17th, 2020

DOI: https://doi.org/10.21203/rs.3.rs-41978/v1

License: (c) (1) This work is licensed under a Creative Commons Attribution 4.0 International License.

Read Full License 


\section{Abstract}

Background: Japan has opened its labor market to care workers from Indonesia under the JapanIndonesia Economic Partnership Agreement (EPA). Many foreign care workers wish to enter Japan to learn skills that they can apply upon returning to work in their home countries. However, little research has examined the types of care skills that could be transferred between countries. In this study, we assessed Indonesian care workers employed at care institutions in Japan and Indonesia to identify discrepancies in their attentiveness toward checking essential points of oral care for older adults.

Methods: A checklist comprising 42 items of universal oral care assessment was developed prior to the study. The checklist was distributed via the Internet to 418 Indonesian EPA care workers in Japan, and via a paper survey to 213 Indonesian care workers in Indonesia. The Mann-Whitney U test was used to compare the distribution of scores for each checklist item in each group.

Results: The respondents comprised 110 Japan-based EPA care workers (response rate: $26.3 \%$ ) and 213 Indonesia-based care workers (response rate: $99.1 \%$ ). Comparing the two groups, Japan-based care workers were significantly more likely to perform environmental observations of their older adult patients $(p<0.001)$ and to check items on the oral care checklist during feeding $(p<0.01)$ and post-meal $(p<$ $0.01)$ periods, while Indonesia-based care workers were more likely to check the overall condition of patients before meals $(p<0.05)$.

Conclusions: Discrepancies between the two groups in checking the essential points of oral care were attributed to differences in laws and regulations governing the care environment. Indonesian care workers employed in Japan have the advantage of learning to provide a more systematic approach to caring for older adults in accordance with Japan's Long-Term Care Act. This approach could contribute to lowering the risk of aspiration pneumonia in Indonesia. A training program designed for returning migrant workers to transfer newly developed oral care skills will be essential for Indonesia to keep pace with the negative impacts of its aging population.

\section{Background}

The movement of care workers across national borders is a global trend. Since 2008, Japan has recruited foreign care workers under economic partnership agreements (EPAs) with Asian countries that began with Indonesia, followed by the Philippines (in 2009) and Vietnam (in 2014). Indonesian care workers who enter Japan under the EPA engage in institutional-based care work and commonly aim for career development there [1] because Japan is one of the most super-aged societies in the world, with prolific experience in providing care for older adults, including oral care. Indonesian care workers in Japan, especially those among the early EPA batch, experienced some friction caused by differences in the cultures of care between the two countries, but most were gradually able to adjust [2]. Japan offers unique learning opportunities for Indonesian care workers, who report high satisfaction with their employment in Japan after returning to Indonesia [3]. 
In the present study, we focused on the potential for transfer of oral care skills, which are essential to satisfy the basic needs of care receivers, such as older adults, who may be at risk of aspiration pneumonia. Aspiration pneumonia is frequently caused by a defective swallowing mechanism, and occurs in patients with malfunctioning deglutition and cough reflex. Older adults are particularly vulnerable to such conditions because of aging, and the disease is the fourth leading cause of death in Japan $[4,5]$. Although there are no specific statistical data on aspiration pneumonia in Indonesia, because it can be caused by frailty of deglutition, it is likely to be found there as well. As part of the effort to combat the negative effects of aging in society, Japanese researchers have developed various approaches to promote proper deglutition, which is influenced by age and bolus size [6], and related to levels of nutrition and activities of daily living, particularly for older adults with sarcopenia [7]. Applying the appropriate trunk position was shown in a clinical setting to be beneficial for shortening oral and pharyngeal transfer times in older adults with dysphasia [8]. These findings suggest that aspiration pneumonia could be prevented via attentive intervention that focuses on maintaining a good posture and a bolus size appropriate for older adults.

Oral care in Japan has begun to evolve to strategically prevent aspiration pneumonia. We propose that improving the level of excellence in care work for older adults overall must involve a combination of careful observation with medical knowledge. Effective management of dysphagia, for example, is particularly important for older adults recovering from stroke or being treated for dementia. Older adults who have experienced a right-hemisphere stroke are likely to ignore the left side of their field of vision because of malfunction in the part of the brain damaged by the stroke. Food that older adults cannot see is likely to remain uneaten; thus, care workers must alert their care receivers to the food, or occasionally turn their plates to help them to see all of their food.

Provision of training in techniques and skills that build upon evidence-based medicine is urgently required by care workers who aid older adults with vulnerability to swallowing dysfunction. It is crucial that care environments for older adults provide appropriate oral care. Effective oral care practices include providing food that care receivers can easily cut to a proper bolus size for swallowing, helping them maintain a good posture when eating, and rearranging the placement of food items to maximize their visual attention. We suggest that the proper adoption of these skills may contribute to lowering the risks of aspiration pneumonia in Indonesia, where the population is expected to age in the coming decades.

The current global era of care worker migration offers a high potential for efficient transfer of care skills between care workers in the sending and receiving countries. However, little research has examined the types of care skills that foreign care workers could learn abroad and then apply when they return to their country of origin. Therefore, we aimed to investigate the potential for transfer of oral care skills for the prevention of aspiration pneumonia from Japan to Indonesia.

\section{Methods}


We studied two groups of care workers for older adults who shared the same nationality (Indonesian) but worked in different countries (Indonesia and Japan) to decrease the potential for cultural or societal context to influence our findings. To understand the oral care settings in Japan and Indonesia, both groups of participants were asked to check the essential points for which they remain aware during provision of oral care for older adults.

\section{Instrument}

We developed an oral care checklist based on a 92-item checklist developed by one of the authors (MH) to prevent aspiration pneumonia [9]. The original checklist was intended for use prior to care provision in Japan, to ensure that patients are able to eat safely. The necessity of developing a checklist that would be immune to cultural differences required several careful discussions between our research team comprising specialists in oral care, public health, and medical sociology/anthropology from Indonesia and Japan. We deleted items for which responses could be biased by cultural or societal context and added items that were universally applicable. The final checklist comprised 42 items divided between two domains (Table 1): 1) observation of the care setting environment and 2) observation of functions and eating capabilities. The first domain contained nine observational items regarding the safety of the care environment for older adults' dietary needs. The second domain was divided into five periods: A) overall condition of the patient before meal (5 items), B) meal preparation period (3 items), C) feeding period (8 items), D) swallowing period (13 items), and E) post-meal period (4 items). A self-report questionnaire that included the oral care checklist and characteristics of the respondents (i.e., gender, age, number of years engaged in care work, and occupation at the care facility), was used in this study. The respondents were asked to provide yes/no responses (yes $=1, \mathrm{no}=0$ ) to indicate that they were attentive to the necessity for care intervention of each item.

\section{Participants}

Eligible participants were Indonesian care workers who worked in public and private care facilities in Indonesia and Japan. In Indonesia, nonprobability purposive sampling was performed to select care workers. In total, 215 care workers from 18 care facilities ( 7 government-owned and 11 privately owned) from four prefectures (Yoghakarta, West Java, DKI Jakarta, and Tangerang Banten) enrolled as participants; 213 completed the survey. All of the participants, including 52 nurses, were engaged in care work. There was no statistical difference in attentiveness in care between nurses and non-nurses based on domain/period-based total scores. Therefore, in the latter part of this study, all samples from Indonesia (hereinafter "Indonesia-based care workers") were tested regardless of their occupational title. In Japan, 418 Indonesian care workers who entered Japan under the certified care worker track designated by the Japan-Indonesia EPA (hereinafter "Japan-based EPA care workers") were recruited through social networking services (Facebook). In total, 110 completed the survey. Because of EPA regulations, all 110 of the participants who enrolled in the study were nurse graduates engaged in care work as follows: 57 (51.8\%) in special nursing homes; 33 (30\%) in healthcare facilities for older adults; 
and $20(18.1 \%)$ in other types of care institutions, including hospitals and special care facilities for people with disabilities.

\section{Data analyses}

Scores for each oral care item were added by domain/period, and within-group analysis of differences between the added scores was conducted using the characteristics of the respondents. Mann-Whitney $U$ tests and chi-square tests were conducted to compare the distribution of each item between Indonesian care workers and Indonesian EPA care workers, and a significance level of $p<0.05$ was applied. We used IBM SPSS Statistics for Windows, Version 25J for the statistical analyses.

\section{Results}

\section{Respondents}

A total of 213 (response rate: 99.1\%) Indonesia-based and 110 (response rate: 26.3\%) Japan-based EPA care workers completed the questionnaire. Average age was significantly higher in the Indonesian care workers based in Indonesia (35.2 years; standard deviation [SD] 11.2) compared with those based in Japan (27.9 years; SD 3.1; $p<0.001)$, as was the duration of work experience (7.3 years; SD 6.6 vs. 3.7 years; SD 2.8, respectively; $p<0.001)$. There was no significant difference in gender distribution by group.

\section{Cross-sectional analysis of respondent characteristics and oral care domain scores}

The domain/period-based total scores for Indonesia-based care workers were tested by institution (public or private) and type of work (nursing or other care work), and no significant correlations were found. For Japan-based EPA care workers, we tested the domain/period-based total scores by type of institution (working in a special nursing home or not), clinical experience as a nurse prior to entering Japan, completion of a care worker training course while in Indonesia, and experience as a care worker prior to entering Japan, and found no significant correlations.

\section{Comparisons between Indonesia-based and Japan-based EPA care workers}

Comparisons of each item on the oral care checklist between Indonesia-based care workers and Japanbased EPA care workers are shown in Table 1. The results indicated that Japan-based EPA care workers were more likely than Indonesia-based care workers to perform environmental observations $(p<0.001)$, specifically during both the feeding $(p<0.001)$ and post-meal $(p<0.001)$ periods. Conversely, Indonesiabased care workers were more likely to check the overall condition of the patient before meals $(p=0.021)$ compared with Japan-based EPA care workers. This was particularly true for the following items: "older adult is in a poor condition/sleep deprivation" ( $p=0.006)$; "older adult has a fever" $(p<0.001)$; "older adult is coughing" ( $p=0.004)$; and "older adult has different blood pressure (higher or lower) and pulse (bradycardia, tachycardia) than usual" ( $p=0.012$ ). To determine whether a nursing background 
contributed to these differences, we compared the proportions of Indonesia-based and Japan-based EPA care workers with nursing backgrounds and found no significant difference between the two groups.

\section{Discussion}

In this study, we compared the quality of oral care provided to older adults by Indonesia-based care workers with Japan-based EPA care workers. Although all of the participants in this study were of a common nationality (Indonesian), there were differences between the groups in the oral care items that participants checked. Apart from the meal preparation and swallowing periods, there were other significant differences between the two groups. Specifically, Japan-based EPA care workers were more likely to make environmental observations during the feeding and post-meal periods, whereas those based in Indonesia were more likely to make observations about the overall condition of their patients before meals. We offer three possible interpretations for these discrepancies.

First, the working environments in these two countries are different. Generally, care workers in Japan have higher caseloads than their counterparts in Indonesia, and are also expected to provide care for several older adults simultaneously. A more hectic schedule might have prevented the Japan-based EPA care workers from focusing on the overall condition of each patient prior to meals. Conversely, the ratio of care workers to older adults is higher in Indonesia compared with Japan, thereby allowing for more time to carefully observe each patient.

Second, regulations that dictate the minimum physical requirements for institution-based care of older adults differ between the two countries. Japan-based EPA care workers are expected to follow all of the rules and regulations established in Japan, with care facilities required to uphold ministerial ordinances. Specifically, Ministerial Ordinance No. 39 (enacted on March 31, 1999) established parameters for the physical environment of a special nursing home. Under this ordinance, a special nursing home must provide a dining room that is larger than three square meters per patient, as well as a number and size of bedrooms appropriate for maintaining proper sanitation and avoiding medical risk. The ordinance also states that food should be provided in a form that meets the physical requirements of each individual older adult. These provisions are crucial for dysphagia management, which requires postural adjustments, swallowing maneuvers, and diet modifications [10-12]. This ordinance has directly led to improvements in the care environment and skill sets of care workers in Japan; by contrast, there is a lack of comparable regulation in Indonesia.

Third, the formal job description and employer expectations for care workers differ between Japan and Indonesia. Having no specific legislation to regulate the role of a care worker in Indonesia, all care workers share in the common work, regardless of their occupational title. In this study, Indonesia-based care workers were comparatively more attentive to the overall condition of their older adult patients, particularly during the pre-meal period. This included checking vital signs including blood pressure, and assessing sleep deprivation, fever and cough. In Japan, such tasks are often under the purview of nurses, and the job descriptions for nurses and care workers are clearly delineated by law. Under this system, a 
nurse is defined as someone who is licensed under the Japanese Ministry of Health, Labour and Welfare to provide medical treatment or to assist in providing medical care for people who are injured, ill or recovering from childbirth [19]. The role of a care worker is broader, being defined as "care worker must in good faith engage in the services so as to allow the persons under their charge to maintain personal dignity and live an independent life in light of their standing at all times" [20]. In accordance with these laws, the duties of care work in Japan are clearly divided: nurses check vital signs (because this is a form of medical care) and care workers assist older adults with activities of daily living that are important to maintain quality of life.

The strengths of the institution-based care environment in Japan were reflected in the differences in practical application of oral care skills between our two study groups. The environmental observations made during the feeding and post-meal periods enabled the Japan-based EPA care workers to be attentive to helping older adults maintain not only oral functioning, but also good posture and motion while eating. Care skills that assist older adults with maintaining a good posture while eating can help prevent dysphasia and decrease pharyngeal residue, and include the "chin down technique" and "head rotation technique," which minimize dysphasia risk by changing the angle of the head [13-16]. Apart from the present study, the authors have routinely observed Japanese care workers instructing their Indonesian EPA counterparts in these very skills.

Another beneficial practice that Indonesian care workers appeared to gain from working in Japan was greater attentiveness to oral care needs, particularly during the post-meal period. Post-meal oral care, such as tooth brushing, is also useful for dysphasia prevention, as reported by Yoneyama et al. [17, 18]. More than $65 \%$ of the Japan-based EPA care workers in this study engaged in oral care during the postmeal period, regardless of care institution. We propose that Indonesian EPA care workers could help their compatriots by transferring these skills to care settings in Indonesia.

Currently, older adults represent $10.1 \%$ of the Indonesian population and the older-age dependency ratio (age 65+/age 15-64) is 9.2\% [21]. The workload for care providers has yet to be overburdened; thus, care providers have the latitude to be flexible when providing care. However, it has been predicted that by the year 2050 the older segment of the Indonesian population will rise to $21.1 \%$, with the older-age dependency ratio skyrocketing to $24.5 \%$. Thus, in the near future, Indonesian society may face some of the same issues that Japan is currently experiencing. The results of our study suggest that Indonesia may benefit from learning some of Japan's recent lessons.

There are important factors to bear in mind when attempting to transfer care skills and practices between these two countries. First, we must remain aware that care work varies in accordance with the cultural and societal setting. As indicated above, there are large discrepancies between Japan and Indonesia in terms of provision and regulation of care, job descriptions for nurses and care workers, and responsibility distribution between care providers. Our study has identified areas in which we need to focus if we are to bridge the gaps in older-age care provision between Japan and Indonesia, assuming that such discrepancies reflect cultural and societal differences in caregiving that can be further scrutinized. 
Accordingly, we must adopt a multidisciplinary approach to the development of a training module for oral care that will involve medical professionals, sociologists and anthropologists. Second, a discussion on the governance of returning migrant workers is a prerequisite for the dissemination of any such training module. Indeed, our ultimate goal is to contribute not only to the well-being of older adults in Indonesia, but also its returning migrant workers. Recently, as part of the launch of the Law on Protection of Migrant Workers (No. 18/2019) [22], the National Agency for the Protection and Placement of International Migrant Workers of Indonesia initiated a program in which returning migrants, particularly those who have engaged in care work in Japan, will serve as leaders in training local care workers and Japan-bound Indonesian care workers. Therefore, establishment of a system to maximize the experiences of care workers as they return from Japan could facilitate the effective transfer of oral care skills to Indonesia in the near future.

\section{Limitations}

There were some limitations to this study. First, the response rate for the Japan-based EPA care workers was low, which made sampling bias unavoidable. This might have occurred because the participants were too busy to respond to the online survey. Second, the sample was limited to institution-based care workers. Further research is required to evaluate the oral care skills of home-based care workers.

\section{Conclusions}

A novel oral care checklist was developed that revealed differences in oral care practices for older adults between care workers based in Indonesia and Indonesian EPA care workers based in Japan. Based on these findings, our research team plans to develop a new training program to help bridge the gaps in oral care provision between these two countries.

\section{List Of Abbreviations}

Economic Partnership Agreement (EPA)

Standard deviation (SD)

\section{Declarations}

\section{Ethics approval and consent to participate}

Ethics approval was granted by the Biomedical Sciences Ethics Board at Nagasaki University (permission number: 19111407)

\section{Consent for publication}




\section{Availability of data and materials}

The datasets generated and/or analyzed during the current study are not publicly available because of ongoing data collection. However, data will be released upon completion of the study and are available from the corresponding author on reasonable request.

\section{Competing interests}

Not applicable.

\section{Funding}

This research was supported by the Economic Research Institute for ASEAN and East Asia.

\section{Authors' contributions}

HY drafted the manuscript; SH conducted the analysis; HM, NS, RT, and HY developed the questionnaire and conducted the survey; and HM and NS provided advice to HY.

\section{Acknowledgments}

We thank the participants of our study. We also thank Michelle Kahmeyer-Gabbe, PhD, from Edanz Group (https://en-author-services.edanzgroup.com/) for editing a draft of this manuscript.

\section{References}

1. Adachi S, Ohno S, Hirano YO, Ogawa R, Kreasita. Real Images and Realities of Indonesian and Filipino Certified Careworker Candidates under the EPA Program. Bul Kyushu Univ Asian Cent. 2010; 5:163-174.https://catalog.lib.kyushu-u.ac.jp/opac_download_md/17935/p163.pdf. Accessed 29 June 2020.

2. Alam B, Wulansari SA. Creative Friction: Some Preliminary considerations on the Socio-Cultural Issues Encountered by Indonesian Nurses in Japan. Bul Kyushu Univ Asian Cent. 2010; 5:183192.https://catalog.lib.kyushu-u.ac.jp/opac_download_md/17937/p183.pdf. Accessed 29 June 2020.

3. Hirano YO, Rahardjo TW, Nugraha S. Nikoku kan keizairenkei kyoutei de tonichi shita indoneshia jin kangoshi kaigofukushishi kouhosha ra no nihon deno keiken (The experience of Indonesian EPA 
nurse and care worker candidates in Japan). Chiiki Kearingu. 2016;6:87-91. (Only in Japanese)

4. Japanese Ministry of Health, Labour and Welfare. Demographic statistics in Japan 2011. https://www.mhlw.go.jp/toukei/saikin/hw/jinkou/kakutei11/dl/10_h6.pdf. Accessed 4 Dec 2019.

5. Teramoto S, Fukuchi Y, Sasaki H, Sato K, Sekizawa K, Matsuse T. High incidence of aspiration pneumonia in community- and hospital-acquired pneumonia in hospitalized patients: a multicenter, prospective study in Japan. J Am Geriatr Soc. 2008; 56(3): 577-93.

6. Higashijima M. Influence of age and bolus size on swallowing function: basic data and assessment method for care and preventive rehabilitation. Am J Occup Ther. 2010; 64(1): 88-94.

7. Shiozu H, Higashijima M, Koga T. Association of sarcopenia with swallowing problems, related to nutrition and activities of daily living of elderly individuals. J Phys Ther Sci. 2015; 27: 393-6.

8. Higashijima M, Murata J, Ueda T, Han M. Clinical advantages of eating positions of the mid-neck on swallowing function. J Phys Ther Sci. 2012; 24:837-40.

9. Higashijima M, Watanabe N. Aspiration Pneumonitis Prevention Today. Tokyo, Ishiyaku Shuppan. 2019.

10. Sura L, Madhavan A, Carnaby G, Crary MA. Dysphagia in the elderly: management and nutritional considerations. Clin Interv Aging. 2012; 7: 287-98.

11. The Oto-Rhino-Laryngological Society of Japan. Clinical practice guidelines for diagnosis and management of dysphagia, 2018. http://www.jibika.or.jp/members/guidelines/enge_shougai_2018.pdf. Accessed 31, Jan 2020.

12. Japanese Society of Gerontology. Manual of oral care management addition. 2010. http://www.gerodontology.jp/publishing/file/manual.pdf. Accessed 31, Jan 2020.

13. Shanahan TK, Logemann JA, Rademaker AW, Pauloski BR, Kahrilas PJ. Chin-down posture effect on aspiration in dysphagic patients. Arch Phys Med Rehabil. 1993; 74(7): 736-9.

14. Rasley A, Logemann JA, Kahrilas PJ, Rademaker AW, Pauloski BR, Dodds WJ. Prevention of barium aspiration during videofluoroscopic swallowing studies: value of change in posture. Am J Roentgenol. 1993; 160: 1005-9.

15. Logemann JA, Gensler G, Robbins J, et al. A randomized study of three interventions for aspiration of thin liquids in patients with dementia or Parkinson's disease. J Speech Lang Hear Res. 2008; 51: 1733 .

16. Logemann JA, Kahrilas PJ, Kobara M, Vakil NB. The benefit of head rotation on pharyngoesophageal dysphagia. Arch Phys Med Rehabil. 1989; 70: 767-71.

17. Yoneyama T, Yoshida M, Matsui T, Sasaki H: Oral care and pneumonia. Lancet 1999; 354: 515.

18. Yoneyama T, Yoshida M, Ohrui T, Mukaiyama H, Okamoto H, et al. Oral care reduces pneumonia in older patients in nursing homes. J Am Geriatr Soc 2002; 50: 430-433.

19. Japanese Law Translation. Act on Public Health Nurses, Midwives, and Nurses. http://www.japaneselawtranslation.go.jp/law/detail/?id=2075\&vm=04\&re=01 Accessed 25 Dec 2019. 
20. Japanese Law Translation: Social Worker and Certified Care Worker Act. http://www.japaneselawtranslation.go.jp/law/detail/?id=2693\&vm=\&re= Accessed 25 Dec 2019.

21. Help age: Ageing Population in Indonesia. http://ageingasia.org/ageing-population-indonesia/ Accessed 25 Dec 2019.

22. International Labour Organization: Law on Protection of Migrant Workers (No. 18/2019). https://www.ilo.org/dyn/natlex/natlex4.detail?p_isn=109279\&p_lang=en. Accessed 29 June 2020.

\section{Table}

Table 1. 
Table 1. Comparison of oral care checklist scores between the two study groups.

\section{Oberretrionalitem}

\begin{tabular}{ccr}
$\begin{array}{c}\text { Indonesian } \\
\text { care warkers in in } \\
\text { Japan } \\
\text { (n= 110) }\end{array}$ & $\begin{array}{c}\text { Indonesian } \\
\text { care workers } \\
\text { in Indonesia } \\
\text { (n= 213) }\end{array}$ & P value \\
$96 \%$ & $55 \%$ & $<0.001$ \\
$91 \%$ & $47 \%$ & $<0.001$ \\
$98 \%$ & - & \\
$98 \%$ & $64 \%$ & $<0.001$ \\
$77 \%$ & $54 \%$ & $<0.001$ \\
$89 \%$ & $44 \%$ & $<0.001$ \\
$66 \%$ & $52 \%$ & 0.008 \\
$28 \%$ & $60 \%$ & $<0.001$ \\
$78 \%$ & $74 \%$ & 0.257 \\
6.2 (SD: 1.4$)$ & 4.5 (SD: 1.9$)$ & $<0.001$ \\
\hline
\end{tabular}

\section{BVIROMMIMTALOBSORVATIONS}

1 There is a separation between the dining rocm and the bedrocm

2 Adjutable dining tables ar special chairs that can be used according to need are available for personal use

${ }_{3}$ There are applicable utensils (e.g. spoons and chopstidss) that can be used to acconmodate the impaiment of the

3 individual user*

4 There are variations in the farm of food (e g. paridge cur into bite size pieces and scft chopped food)

5 There is vatable muxus suction

${ }_{6}$ There is a tool that can be used by care warkers or patients to notify other care warkers if there is anemergenry

6 (e.g.. a bell)

7 Numbers of care warkers and older adults are balanced when conducting meal swervision

8 There is an allocation of one care worker for everv care receiver whoreoumes total caretto

9 The care wolke1s understand the dietary needs of each receiver

Total scoire II OBSERVATON OF PHYSTOLOGCFUNCIION AND EATING CAPABLIMIS

\begin{tabular}{|c|c|c|c|}
\hline \multicolumn{4}{|l|}{ A Overall condition before eating } \\
\hline 1 Older adult moves differentlv than usual & $72 \%$ & $58 \%$ & 0.009 \\
\hline 3 Odder adult has fever & $20 \%$ & $50 \%$ & $<0.001$ \\
\hline 5 Clder adult has different blood pressure (higher or bwer) and pulse (bradycardia tachrcandia) than usual & $36 \%$ & $49 \%$ & 0.012 \\
\hline Total score & 2.0 (SD: 1.4$)$ & $2.6(\mathrm{SD}: 2.0)$ & 0.021 \\
\hline \multicolumn{4}{|l|}{ B Meal preparation period: Waiting time between arrival of food and serving of food. } \\
\hline$\$$ Odder adult swoears calm & $40 \%$ & $55 \%$ & 0.008 \\
\hline Total scoire & 1.5 (SD: 1.2$)$ & $1.5(\mathrm{SD}: 1.2)$ & 0.839 \\
\hline \multicolumn{4}{|l|}{ C Feeding period. } \\
\hline 1 The dining table caunct be set wo in accardance with the bodily vocitions of older adult & $82 \%$ & $49 \%$ & $<0.001$ \\
\hline 2 There are difficulites when eating (e.g., caunct use a soocu for food or hold food) & $79 \%$ & $65 \%$ & 0.007 \\
\hline 7 Odder adult camnot ask for help when having difficulties during the eatirg process & $55 \%$ & $44^{2} \%$ & 0.035 \\
\hline 8 Odder adult refuses to be hebed when eating ( $e g$. does not want to coen the mouth or feed themselves) & $63 \%$ & $49 \%$ & 0.014 \\
\hline Total score & 5.7 (SD: 1.9$)$ & $4.4(\mathrm{SD}: 2.9)$ & $<0.001$ \\
\hline \multicolumn{4}{|l|}{ D Swallowing period. } \\
\hline 1 Older adult cannot take in food smocthly (e.a. lips cannot dose $\alpha$ food fills our of the mouth) & $58 \%$ & $54 \%$ & 0.302 \\
\hline $\begin{array}{l}2 \text { There are problems with chewing (e } g \text {. ladk of chewing, remoing or leating hard fod. very fond of eating scft fod. } \\
\text { onlv. cr chewing for a bre time) }\end{array}$ & $70 \%$ & $66 \%$ & 0.287 \\
\hline 3 Odder adult cannot chew food into appropriate shewes and sizes to be swallowed. & $59 \%$ & $59 \%$ & 0.52 \\
\hline 4 Odder adult hoards food in the mouth le.g. stcres food in the mouth but does not swallowi & $65 \%$ & $57 \%$ & 0.083 \\
\hline 5 There are oroblems in the vrocess of swallowire food (e. g.. camot swallow food ar takes time to swallow food) & $71 \%$ & $54^{2} \%$ & 0.002 \\
\hline 6 There is a swallowing discrder ( $e . g$. food caunot be channeled into the esophagus) & $46 \%$ & $46^{2} \%$ & 0.535 \\
\hline 7 There is a sound of fluid in the esophagus & $43 \%$ & $47 \%$ & 0.3 \\
\hline 1 Older adult does not brush teeth after meals & $41 \%$ & $32 \%$ & 0.07 \\
\hline 2 There is shartness of breath after meals & $29 \%$ & $45 \%$ & 0.005 \\
\hline 3 Odder adult cannot use a tocthintsh & $66 \%$ & $40 \%$ & $<0.001$ \\
\hline 4 There is leftover food after brushing teeth & $69 \%$ & $40 \%$ & $<0.001$ \\
\hline Total score & 2.1 (SD: 1.3$)$ & $1.6(\mathrm{SD}: 1.2)$ & 0.001 \\
\hline
\end{tabular}

Scoring system: $1=$ yes; $0=$ no

"This item was onitted fiom the ouestionnaire for care workers in Indonesis

* This item was translated to read "There are special nurses who are responsible for dder adults with total care" in the Indonesian version to suit the enviroment of the care setting in Indonesia 